\title{
Comparison Effects of Three Burden Methods Using Maximum Burdens in Increasing the Maximum Strength and Muscle Hypertrophy Non-Athlete Men
}

\author{
Mohammadbagher Forghani Ozrudi* \\ Young Researchers and Elite Club, Islamic Azad University, Iran \\ *Corresponding author: Mohammadbagher Forghani Ozrudi, Young Researchers and Elite Club, Qaemshahr Branch, Islamic Azad University, \\ Qaemshahr, Iran
}

Submission: 非 December 07, 2017; Published: 眥 March 12, 2018

\begin{abstract}
The purpose of this investigation is comparing the effects of three admitting models using maximum admits in increasing the maximum strength and hypertrophy of unexercised men in the muscles of arm forth. Statistical sample of this investigation are 45 non-athlete male students of Mazandaran University of Science and Technology of the Department of Public Physical Education. Maximum strength and the mass of muscles in the sample was measured using the maximum repeating test in moving arm form by Haler or measured using the arm, before and after the match. Then, the samples were grouped in 3 empirical groups (15 per groups). They exercised for 8 weeks, 3 sessions per week, and 75 minutes per session. The data were analyzed by variance and (LSD) by using SPSS20 software ( $p \leq 0.05)$. There was no meaningful difference among 3 models; normally pyramidal, Counter-pyramidal, and Flat-pyramidal in increasing the shape of arm forth. Also, there was a meaningful difference between two methods, pyramids and flat-pyramid after the test. There was no meaningful difference among the methods between counter-pyramidal and flat-pyramidal. So, we can suggest that when the purpose is increasing the muscle, we can use every method, but if the purpose is increasing the strength, it is prefer to use flat pyramidal method.
\end{abstract}

Keywords: Maximum admit; Maximum strength; Hypertrophy; Admitting model; Non-athlete male

\section{Introduction}

Power is affecting sports performance assist the body in maintaining healthy skeletal-muscle, preventing disease and abnormalities of the skeletal-muscle and reduced muscle injury, arthritis patients is essential. Several variable effectiveness of a resistance training exercise to achieve optimum results in increased power set $[1,2]$. Generally, different methods, in strength exercises, have two important purposes: increasing the maximum strength and increasing the muscle size (hypertrophy). The exercises with high intensity ( $80-90 \%$ of a maximum repeat), less repeating ( 2 to 8 repeats), and long intervals ( 2 to 5 minutes), is done for increasing the maximum strength and mid-high intensity exercises (70 to 80 percent of a maximum repeat), more repeating number (8 to 15) and shorter intervals ( 30 seconds to 2 minutes), to increase the size or hypertrophy of muscles [3,4]. It is noted that we cannot separate different protocols in strength exercises, but we can say that every purpose is used as a main purpose in every program, so the results of these exercises for increasing strength and hypertrophy different with. The recommendations of American Collage (ACSM), National strength committee (NSCA) and other researchers, but (ACSM) introduced maximum admits (80-100\% of IRM) as intensity range of exercise for increasing strength and maximum admits (70-100\% of IRM) as intensity range of exercise for increasing hypertrophy [4]. Most studies which recommend using maximal admits for increasing strength [4-6], believe that using maximal admit, we can exercise units [7]. Despite, [8] suggested that matching the muscular strength using maximal admittance $(80-85 \%$ of IRM) is very important. This is important because neurotic homogenization in plays an important role in improving muscular strength and it is prior to hypertrophy for an identified period although movement activity increases in the last repetition, when the man is tired [9]. Several studies which recommended resistance exercise for increasing muscular strength and also physical collage in America and national committee, have recommended using maximal burden as an optimal method for increasing the maximal strength $[4,6,10,11]$. As it mentioned above, our purpose is comparing 3 different methods of resistance exercise on the strength and hypertrophy of muscles in non-athlete men.

\section{Materials and Methods}

This study is semi-empirical and it is performed as a field study. 45 male are chosen randomly, who were non-athlete male students 
of Mazandaran University of Science and Technology of the Department of Public Physical Education, but they did not exercise by halter. They were known by the correct techniques in haltering after measuring their weight and their height. Before this period, all of them attended in resistance exercises with mid-intensity (40$60 \%$ of $1 \mathrm{RM}$ ) for 8 weeks (2 sessions per week) with 3 minutes intervals, to consider their physical, matches and preparation in maximal burdens [12]. In this period, we used the movements for supporting the main parts of body for movement and also central part of body. Then, their maximal strength was measured by maximal repetition test (1RM), by halter. Also, it is measured the size of arm by a meter. Then, the circumstance of arm was calculated by Ferrisencho (1974) method. The circumstance of muscles of arm $(\mathrm{mm})=[$ circumstance of arm $(\mathrm{mm})$-the thickness of skin wrinkle on the $\operatorname{arm}(\mathrm{mm})]$. Also, the skin wrinkle on the arm was measured by Lange Calibration. Then, the samples were grouped into 3 exercise groups, based on their maximal strength; first group (15 people, pyramidal), second group (15 people, contrary pyramidal), third group (15 people, flat pyramidal). In this period, the scale of was the same for all three groups by this formula: (sets* Repetitions*
$\%$ RM) [13]. Then, they exercised for 8 weeks, 3 sessions per week, and 75 minutes per session. The group pyramidal performed in 5 times with the intensity of $(80,85.5,90.3,95.2,100.1 \%)$, the group contrary pyramidal in 5 times with the intensity of $(100.1,95.2$, $90.3,85.5,80.7 \%$ ), and the group flat pyramidal in 6 times with the intensity $(80.5,4 * 90.2,85.5 \%)$ [14]. Also the interval duration for each group among times was 3 minutes and among movements was 2 minutes. After 8 weeks, the program of main exercise (maximal strength) and the muscular size of them were measured. After getting data, we used descriptive statistics to determine the central dispersal index. After extracting the data, descriptive statistics for the central scattering parameters (mean and standard deviation) was used. Part of the inferential tests, ANOVA and post-hoc test (LSD) to determine differences between groups using the software SPSS20 in significance level $(\mathrm{p}<0.05)$ were used.

\section{Results}

Table 1 shows the main and SD of maximal strength (kg) and the muscular size (mm) of the samples before and after the test.

Table 1: The main and SD of maximal strength $(\mathrm{kg})$ and the muscular size $(\mathrm{mm})$ of the samples before and after the test.

\begin{tabular}{|c|c|c|c|c|c|c|}
\hline \multirow[t]{2}{*}{ Variable Group } & \multicolumn{2}{|c|}{ Pyramidal } & \multicolumn{2}{|c|}{ Contrary-Pyramidal } & \multirow{2}{*}{$\begin{array}{c}\text { Flat- Pyramidal } \\
\text { Pretest }\end{array}$} & \multirow[b]{2}{*}{ Posttest } \\
\hline & Pretest & Posttest & Pretest & Posttest & & \\
\hline Maximal strength & $17.93 \pm 4.16$ & $23.7 \pm 4.82$ & $18.13 \pm 4.52$ & $25.53 \pm 4.15$ & $17.53 \pm 5.82$ & $28.63 \pm 5.48$ \\
\hline Muscular size & $212.41 \pm 15.03$ & $214.61 \pm 15.2$ & $217 \pm 35.01$ & $220.07 \pm 34.69$ & $218.2 \pm 28.39$ & $224.27 \pm 27.69$ \\
\hline
\end{tabular}

Table 2: The results of one way variance to compare maximal strength, and the muscular size $(\mathrm{mm})$ in pre-test and post test.

\begin{tabular}{|c|c|c|c|c|c|c|}
\hline \multicolumn{2}{|c|}{ Variations Source } & Total of Squares & DF & Total Main & $\mathbf{F}$ & Meaning Level \\
\hline $\begin{array}{c}\text { Pretest arm forth } \\
\text { (1RM) }\end{array}$ & $\begin{array}{l}\text { Inter group } \\
\text { Intra group } \\
\quad \text { Total }\end{array}$ & $\begin{array}{c}2.8 \\
1029.9 \\
1032.7\end{array}$ & $\begin{array}{c}2 \\
42 \\
44 \\
\end{array}$ & $\begin{array}{c}1.4 \\
24.521\end{array}$ & 0.057 & 0.945 \\
\hline $\begin{array}{c}\text { Pretest arm forth } \\
(1 \mathrm{RM})\end{array}$ & $\begin{array}{l}\text { Inter group } \\
\text { Intra group } \\
\text { Total }\end{array}$ & $\begin{array}{c}186.544 \\
988.867 \\
1175.411\end{array}$ & $\begin{array}{c}2 \\
42 \\
44\end{array}$ & $\begin{array}{l}93.272 \\
23.544\end{array}$ & 3.962 & 0.027 \\
\hline $\begin{array}{l}\text { Muscular size } \\
\text { Pretest Arm forth }\end{array}$ & $\begin{array}{l}\text { Inter group } \\
\text { Intra group } \\
\text { Total }\end{array}$ & $\begin{array}{c}279.632 \\
31616.67 \\
31896.3\end{array}$ & $\begin{array}{c}2 \\
42 \\
44\end{array}$ & $\begin{array}{l}139.816 \\
752.778\end{array}$ & 0.186 & 0.831 \\
\hline $\begin{array}{c}\text { Muscular size } \\
\text { posttest arm forth }\end{array}$ & $\begin{array}{l}\text { Inter group } \\
\text { Intra group } \\
\quad \text { Total }\end{array}$ & $\begin{array}{c}704.424 \\
30823.69 \\
31528.12\end{array}$ & $\begin{array}{c}2 \\
42 \\
44\end{array}$ & $\begin{array}{l}352.212 \\
733.897\end{array}$ & 0.48 & 0.622 \\
\hline
\end{tabular}

Table 3: The result of LSD to determine the place and the difference of maximal strength in post test (kg).

\begin{tabular}{|c|c|c|c|c|}
\hline Group I & Group J & Average Variation (I_J) & SD & Meaningful Level \\
\hline \multirow{2}{*}{ Pyramidal } & Contrary-pyramidal & -1.83 & 1.77 & 0.307 \\
\cline { 2 - 5 } & Flat-pyramidal & -4.93 & 1.77 & 0.008 \\
\hline Contrary-pyramidal & Flat-pyramidal & -3.1 & 1.77 & 0.087 \\
\hline
\end{tabular}

As it shows in Table 2, according to the statistics and the least meaningful level of table, there is a meaningful difference between post test marks in maximal strength $(\mathrm{kg})(\mathrm{F}=3.962, \mathrm{p}<0.027)$ with $\mathrm{p}<0.05$, but the evidence and the least meaningful level of the table did not show any meaningful difference between the marks in post test in muscular size $(\mathrm{mm})(\mathrm{F}=0.480, \mathrm{p}<0.622)$ with $\mathrm{p} \leq 0.05$.

To understand the difference of maximal strength among groups in post test $(\mathrm{kg})$ of arm forth, we used LSD according to the Table 3, there is a meaningful difference between 2 methods, pyramidal and flat-pyramidal methods $(p<0.008)$.This difference 
is in the maximal strength in the post test of arm forth movement $(p<0.05)$, but there is no meaningful difference between pyramidal method with contrary pyramidal $(\mathrm{p}<0.307)$ and contrary pyramidal with flat- pyramidal $(\mathrm{p}<0.087)$.

\section{Discussion and Conclusion}

The findings of the first study showed that there is no meaningful difference among 3 pyramidal, contrary-pyramidal and flat-pyramidal models in increase the muscular size of arm forth. This fining is according to the findings of Chesnut \& Decherti (1999), Wernbom et al. [15]. Although the 3 groups used difference methods, all of them exercised the same. Of course comparing the variation average in muscular size of arm forth ( $\mathrm{mm}$ ) shows that the flat pyramidal group (6.70) increase more than 2 other pyramidal (2.2) and contrary pyramidal (3.70) groups. One probable reason is the more times of flat pyramidal group (6 times) comparing to the 2 other groups (5 times). According to the second finding of study, there is a meaningful difference in maximal strength of arm forth in post test in the pyramidal and flat pyramidal group. This result is according to the Bompa [12] result. The best model to obtain maximal strength is the flat pyramidal model. The physiologic of flat pyramidal model is good that muscular-nervous matches are made by fixed burden without creating disorders in body. One reason for this is choosing the more numbers of flatpyramidal group ( 6 times), comparing to the pyramidal group ( 5 times). The fans of using maximal burden believe that the model of special movements (movement with high move) is not obtained by lifting light to mid-weighs and we should use maximal burden [16]. Also there is no meaningful difference among pyramidal, contrary-pyramidal and flat-pyramidal methods. One reason for deciding one of these methods, pyramidal, contrary-pyramidal is using the similar burden. About the effects of these two methods, last studies reported paradoxical results. One important reason for this is because of individual difference, stimulus, their feeding and also the differences in the intensity, size and the kind of exercise and finally the muscular groups in the exercise. So, according to the finding we can say that when the purpose of exercise is the increase in muscular size, we can use all these three models, but when the purpose is the increase in maximal strength, using flat pyramidal model is better than pyramidal one, and also we can use both pyramidal and contrary pyramidal method, but we should consider that using maximal burden with every method needs that the person is prepared in physical education, so it is suggested that the beginner use the light to mid-weighs.

\section{References}

1. Gaeini AA, Arzi H, Esmaeili J (2009) Compare weight training (pyramid and inverted pyramid) on the pectoral muscle strength in athlete's beginner. Journal of movement 35: 129-141.

2. Forghani Ozrudi MB, Fathi Shob SA, Rahimi Aliabadi S (2014) Comparison of three methods of weight training to increase the power of the male students of mazandaran university of science and technology. International Journal of Applied Exercise Physiology 3(1): 53-59.

3. Bompa T, Di Pasquale MG, Cornacchia L (2002) Serious strength training. Human Kinetics, USA.

4. American College of Sports Medicine (2002) American College of Sports Medicine Position stand: progression models in resistance training for healthy adults. Med Sci Sports Exerc 34(3): 364-380.

5. Kraemer WJ (1983) Exercise prescription in weight training: manipulating program variables. Natl Strength Cond Assoc J 5(3): 58-61.

6. Kraemer WJ, Ratamess NA (2004) Fundamentals of resistance training: Progression and exercise prescription. Med Sci Sports Exerc 36(4): 674688.

7. Milner-Brown HS, Stein RB, Yemm R (1973) The orderly recruitment of human motor units during voluntary contraction. Journal of Physiology 230(2): 359-370.

8. Häkkinen K, Alen M, Komi PV (1985) Changes in isometric force-and relaxation time, electromyographic and muscle fibre characteristics of human skeletal muscle during strength training and detraining. Acta Physiol Scand 125(4): 573-585.

9. Folland JP, Williams AG (2007) The adaptations to strength training morphological and neurological contributions to increased strength. Sports Med 37(2): 145-168.

10. Deschenes MR, Kraemer WJ (2002) Performance and physiologic adaptations to resistance training. Am J Phys Med Rehabil 81(11): 3-16.

11. Bird SP, Tarpenning KM, Marino FKE (2005) Designing resistance training programmes to enhance muscular fitness. A review of the acute programme variables. Sports Med 35(10): 841-851.

12. Bompa $T$ (1999) Periodization training for sports. Human kinetic publisher, USA, pp. 52-56.

13. Jeff chandler T, Brown L (2007) Conditioning for strength and human performance. LWW publisher, USA, pp. 50-200.

14. Pruitt LA, Taaffe DR, Marcus R (1995) Effects of a one-year high-intensity versus low intensity resistance training program on bone mineral density in older women. J Bone Min Res 10(11): 1788-1795.

15. Wernbom M, Augustsson J, Thome'e R (2007) The influence of frequency, intensity, volume and mode of strength training on whole muscle crosssectional area in humans. Sports Med 37(3): 225-264.

16. Ploutz LL, Tesch PA, Biro RL, Dudly GA (1994) Effect of resistance training on muscle use during exercise. J Appl Physiol 76(4): 1675-1681.
Creative Commons Attribution 4.0 International License

For possible submissions Click Here Submit Article

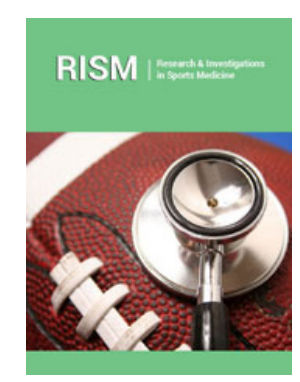

Research \& Investigations in Sports Medicine

Benefits of Publishing with us

- High-level peer review and editorial services

- Freely accessible online immediately upon publication

- Authors retain the copyright to their work

- Licensing it under a Creative Commons license

- Visibility through different online platforms 